\title{
A PRÁTICA COMO COMPONENTE CURRICULAR NO CONTEXTO DAS POLÍTICAS E DA FORMAÇÃO DOCENTE EM GEOGRAFIA
}

\author{
The practice as a curricular component in the context of policies and teaching training in \\ geography \\ João Carlos de Lima Neto* \\ * Professor do Centro de Educação de Jovens e Adultos Antonio Casagrande - joaocaarlos@hotmail.com. \\ Recebido em 03/08/2018. Aceito para publicação em 25/08/2018. \\ Versão online publicada em 20/11/2018 (http://seer.ufrgs.br/paraonde)
}

\begin{abstract}
Resumo:
Neste texto são apresentados parte dos resultados da pesquisa de mestrado intitulada "A Prática como Componente Curricular (PCC) na formação de professores de Geografia" desenvolvida no âmbito do Programa de Pós-graduação em Geografia do Instituto de Estudos Sócio-Ambientais da Universidade Federal de Goiás, com o objetivo de compreender a concepção de PCC sistematizada na legislação pertinente e em projetos pedagógicos de cursos de licenciatura em Geografia do Estado de Goiás. As discussões apresentadas resultam das análises dos documentos oficiais que normatizam a formação de professores no Brasil e dos projetos pedagógicos de cursos de licenciatura em Geografia de duas universidades públicas do Estado de Goiás.
\end{abstract}

Palavras-chave: Formação de professores; Prática como Componente Curricular; Licenciatura em Geografia.

\begin{abstract}
This paper presents part of the results of the master's research entitled "The Practice as a curricular component (PCC) in the training of teachers of Geography" developed under the Postgraduate Program in Geography of the Instituto de Estudos Sócio-Ambientais of the Federal University of Goiás, with the objective of understanding the conception of PCC systematized in the pertinent legislation and in pedagogical projects of undergraduate courses in Geography of the State of Goiás. The discussions presented result from the analysis of the official documents that regulate the training of teachers in Brazil and the pedagogical projects of courses in Geography degree of two public universities in the state of Goiás.
\end{abstract}

Key-words: Teacher training; Practice as a Curricular Component; Degree in Geography.

\section{Introdução}

Neste texto são apresentadas discussões sobre a concepção de Prática como Componente Curricular (PCC) sistematizada na legislação pertinente e em Projetos Pedagógicos de cursos de licenciatura em Geografia do Estado de Goiás. A discussão tecida apresenta parte dos resultados da pesquisa de mestrado "A Prática como Componente Curricular (PCC) na formação de professores de Geografia" desenvolvida no Programa de Pós-graduação em Geografia do Instituto de Estudos SócioAmbientais da Universidade Federal de Goiás e tem como base a análise dos textos curriculares que regulamentam o desenvolvimento dos cursos de formação de professores e que estabelecem a Prática como Componente Curricular destes. A publicação da Lei de Diretrizes e Bases da Educação LDB (Lei 9.394/1996) é o marco inicial adotado para a análise documental, uma vez que foi em seu Art. $65^{\circ}$ que a obrigatoriedade da PCC nos cursos de licenciatura começa a ser delineada. 
Esta pesquisa documental centrou-se, efetivamente, na análise das Diretrizes Curriculares Nacionais para a Formação de Professores da Educação Básica - DCNs (Resoluções CNE/ CP 01/2002 e 02/2015); da Resolução CNE/ CP 02/2002 (que institui a duração e a carga horária dos cursos de Licenciatura, de graduação plena, de formação de professores da Educação Básica em nível superior), do Parecer CNE/ CP 15/2005 (que esclarece as resoluções CNE/CP 01/2002 e CNE/CP 02/2002) e dos Projetos Pedagógicos de Curso de Licenciatura em Geografia das instituições de ensino pesquisadas (Universidade Federal de Goiás e Universidade Estadual de Goiás) em vigência.

\section{A prática nas políticas de formação de professores e sua gênese como componente curricular}

Desde a LDB, as resoluções e pareceres do Conselho Nacional de Educação suscitam os argumentos de que a dicotomia existente na relação entre teoria e prática deve ser superada, tema que também perpassa as discussões travadas no âmbito da comunidade epistêmica de formação de professores no Brasil. A LDB estabelece a articulação entre teoria e prática como eixo central da formação dos professores como profissionais prático-reflexivos e as DCNs argumentam em defesa da formação baseada em três princípios: competência, simetria invertida e pesquisa (CAMPOS, 2002; CURADO SILVA, 2002).

As DCNs ressaltam a aprendizagem por competências como possibilidade de enfrentamento da dicotomia entre teoria e prática. Neste documento, a competência é compreendida como uma capacidade de mobilizar "os conhecimentos adquiridos na reflexão sobre as questões pedagógicas e aquelas construídas na vida profissional e pessoal para responder as diferentes demandas das situações de trabalho" (BRASIL, 2001, p. 26). Em outras palavras, a competência é entendida como um saber fazer docente.

De acordo com Curado Silva (2002) no processo de elaboração destes documentos e, em decorrência deste, na redefinição curricular dos cursos de licenciatura, o termo competência foi utilizado para justificar a necessidade de atribuir sentidos aos saberes escolares, enfatizando a dimensão técnica do saber fazer docente, inserindo-se em uma perspectiva utilitária e imediatista do processo formativo do professor. 0 preparo do professor, nesta perspectiva, dar-se-á no exercício de práticas de sala de aula, aprendendo o que vai ensinar. Destaca-se que, sobre o termo competências, amplamente difundido nos textos curriculares em diversos países, recai uma visão instrumentalista de um saber-fazer docente.

De acordo com Dias (2009, p. 187), as DCNs consolidaram o conceito de simetria invertida, pautado na ideia de que "o professor necessita experimentar, como aluno, o que futuramente irá desenvolver na atuação docente, exercitando-se em experiências análogas àquelas que irá desenvolver com sua classe de alunos". Propõe-se que haja uma coerência na interrelação entre os fundamentos teóricos estudados e a prática que deve ser vivenciada no decorrer da realização do curso. A ênfase na simetria invertida, que também se faz presente nos discursos da comunidade epistêmica, é a pauta da organização dos conteúdos nos currículos dos cursos.

Neste processo de reorganização curricular dos cursos, o destaque nas competências aliado a ênfase dada à simetria invertida ocasionou o "estreitamento da formação" (CURADO SILVA, 2002, p. 35), fazendo com que toda a organização do curso, seus conteúdos e metodologias, fossem direcionados ao contexto de trabalho, à sala de aula na educação básica. De acordo com a autora supracitada, este termo é usado nas diretrizes para indicar que seja antecipada a experimentação de situações específicas do contexto profissional.

Resultante também de disputas discursivas entre diferentes grupos, os quais defendem a figura do professor-pesquisador, a pesquisa como princípio formativo docente tem destaque na legislação, que a reconhece como futura atitude cotidiana estritamente relacionada à atuação do professor na educação básica. De acordo com as DCNs, a pesquisa na formação de professores deve ser ressignificada, vinculando-se à prática e ao contexto de atuação profissional e diferenciando-se da pesquisa acadêmica desenvolvida nas universidades (BRASIL, 2002a).

Para0nde!?, Porto Alegre, v.10, n.2, p.28-35, 2018. Edição Especial com artigos publicados originalmente na XII ENANPEGE http://seer.ufrgs.br/paraonde 
Cabe às instituições de ensino superior, em especial as universidades, formar o profissional dotado de uma competência interrogativa, que se revele um pesquisador de sua própria prática. Neste sentido, a pesquisa assume lugar de destaque e deve permear toda a formação do professor com vista a desenvolver neste as competências de um pesquisador. Esta concepção de formação do professor pesquisador é influenciada pelas formulações de Kenneth Zeichner que, ao defender a pesquisa-ação como princípio educativo nos cursos de formação de professores, a compreende como estratégia de ensino e como instrumento de transformação social (SILVA, 2013).

No âmbito da legislação, corroborando com as demandas disputadas nos discursos da comunidade epistêmica, a prática é definida nas DCNs (BRASIL, 2002a) e nos Pareceres e Resoluções do Conselho Nacional de Educação (BRASIL, 2002b; 2005) como componente curricular dos cursos de licenciatura, voltada para a superação das dificuldades deparadas na relação entre teoria e prática, para além dos Estágios Curriculares Supervisionados, os quais já integram os currículos da formação de professores no Brasil desde a década de 1960.

Desde sua primeira explanação, ainda sob a definição de 'prática de ensino', na LDB em 1996, a PCC recebeu novos contornos que a consolidaram como um importante instrumento na reorganização curricular dos cursos de licenciatura no Brasil. Até o ano de 1996 os cursos de formação de professores tinham como componente curricular 'Práticas de Ensino sob forma de Estágio Supervisionado' e, a partir do Art. 65ํ da LDB, com a inclusão de 300 (trezentas) horas de práticas de ensino para além dos estágios supervisionados, é que a concepção de 'prática' como componente curricular começa a ser delineada. Portanto, do ponto de vista jurídico e normativo, este é o marco inicial de definição da PCC.

A expressão 'Prática como Componente Curricular' (PCC) foi explicitada, inicialmente, apenas na Resolução CNE/CP 02/2002 em 19 de fevereiro de 2002, que instituiu a duração e a carga horária dos cursos de formação de professores para a Educação Básica, em que o Estágio Curricular Supervisionado e a Prática como Componente Curricular aparecem de modo distinto e contempladas com cargas horárias específicas no currículo dos cursos. De acordo com esta resolução, os cursos de licenciatura deveriam integralizar, no mínimo, 2.800 (duas mil e oitocentas) horas, sendo 1.800 (mil e oitocentas) horas de aulas para os conteúdos de natureza científico-cultural, 400 (quatrocentas) horas de estágio curricular supervisionado, 400 (quatrocentas) horas de prática como componente curricular e d) 200 (duzentas) horas para atividades acadêmicas-científico-culturais (BRASIL, 2002b) em um período mínimo de três anos.

Bem como destaca Diniz-Pereira (2011) o intuito de adotar essa expressão no documento foi de destacar a diferença entre 'Prática como Componente Curricular' e 'estágio curricular supervisionado' e reforçar o princípio da articulação teoria e prática. Posteriormente, em 2005, o Conselho Nacional de Educação publicou o Parecer CNE/CP 15/2005 e esclareceu a distinção entre ambas. No contexto destes esclarecimentos, ficou evidente que a PCC não pode ser compreendida e nem confundida como Estágio Curricular Supervisionado e nem ficar restrita às disciplinas de formação pedagógica.

A PCC se difere do Estágio Curricular Supervisionado, ainda que possuam semelhante carga horária, em função do período destinado ao seu desenvolvimento (o estágio é desenvolvido nos dois últimos anos do curso e a PCC é distribuída nas disciplinas ao longo de todo o curso), da duração (o estágio é realizado em um tempo mais concentrado enquanto a PCC deve permear todo o processo formativo) e do formato de orientação e supervisão (o estágio é orientado pela instituição formadora e supervisionado pela escola de educação básica e a PCC é orientada e supervisionada unicamente pela universidade).

Deve ser um componente obrigatório e articulado às disciplinas do currículo do curso, permeando todo o processo formativo do/a licenciando/a, constituindo, assim, um importante referencial que deveria orientar a reestruturação curricular dos cursos de formação docente (SOUZA NETO; SILVA, 2014). Na perspectiva da legislação e ressaltada pelos autores, essa prática curricular deve ser compreendida como um projeto integrador para o currículo dos cursos, enfatizando a prática como lugar de formação e articulação de saberes, devendo propiciar a integração entre conhecimentos teóricos e práticos. A concepção de Prática como Componente Curricular sistematizada nestes documentos é influenciada pelas proposições sobre o papel do professor como prático reflexivo e

ParaOnde!?, Porto Alegre, v.10, n.2, p.28-35, 2018. Edição Especial com artigos publicados originalmente na XII ENANPEGE http://seer.ufrgs.br/paraonde 
aula prática (SCHON, 2000), competências (PERRENOUD, 2001) e simetria invertida, sendo defendida como uma prática que deve permear todo o processo formativo, com início já nos primeiros períodos do curso, em que sejam desenvolvidos exercícios que priorizem a pesquisa e a reflexão na e sobre a atividade profissional.

Passadas uma década da publicação do Parecer CNE/ CS 15/2005, em julho de 2015, o Conselho Nacional de Educação publicou a Resolução CNE/ CP 02/2015 que define as novas, e atuais, Diretrizes Curriculares Nacionais para a Formação de Professores da Educação Básica. Nesta, é alterada a carga horária mínima de integralização curricular para os cursos de licenciatura, que passa a ser de, no mínimo, 3.200 (três mil e duzentas horas) com duração mínima de quatro anos, equiparando-se às diretrizes que normatizam os cursos de bacharelado, mantendo-se a obrigatoriedade das 400 (quatrocentas) horas em atividades de PCC.

Destaca-se, por sua vez, que é nas Diretrizes Curriculares Nacionais para a Formação de Professores publicada em 2015 que a práxis é adotada como expressão da articulação entre teoria e prática. Esta concepção perpassa uma compreensão de formação baseada em uma relação dialética entre teoria e prática, sinalizando para uma ampliação no entendimento desta relação. São, também, consolidadas novas demandas, que foram disputadas no campo epistemológico da formação de professores durante a primeira década do século XXI, a exemplo das diversidades étnico-racial, de gênero, sexual e religiosa, da Língua Brasileira de Sinais e da Educação Especial, que até então eram definidas em legislações específicas.

Sendo a PCC um importante componente relacionado ao exercício docente, deve estar presente e permear todas as disciplinas da matriz curricular dos cursos, articulando conhecimentos específicos da área de formação às particularidades e objetivos destes conhecimentos na educação básica. Deste modo, se constitui como um espaço de reflexão sobre os conhecimentos, os objetivos, os contextos e os dilemas que permearão a prática profissional do futuro professor, colocando-o em contato com questões relacionadas à prática docente e aos problemas da profissão.

Diante do exposto e buscando compreender a recontextualização (BERNSTEIN, 1996) destas discussões no âmbito da formação de professores em Geografia, é apresentada no próximo item uma análise em torno das concepções de PCC sistematizadas em Projetos Pedagógicos de dois cursos de Licenciatura em Geografia de Instituições de Ensino Superior (IES) públicas do Estado de Goiás Universidade Estadual de Goiás (Campus de Ciências Sócio-Econômicas e Humanas) e Universidade Federal de Goiás (Instituto de Estudos Sócio-Ambientais).

\section{Prática como componente curricular na licenciatura em geografia}

No contexto das reflexões apresentadas, direcionamos a discussão para a formação docente em Geografia, enfatizando o debate em torno da análise dos Projetos Pedagógicos dos Cursos (PPC) de Licenciatura em Geografia, do Campus de Ciências Sócio-Econômicas e Humanas da Universidade Estadual de Goiás e do Instituto de Estudos Sócio-Ambientais da Universidade Federal de Goiás. Esta análise é fundamental para a compreensão das implicações da PCC na formação docente em Geografia, uma vez que são nestes documentos que as políticas curriculares são recontextualizadas (BERNSTEIN, 1996), tornando-o instrumento balizador das práticas pedagógicas dos professores formadores.

Com o objetivo de identificar a concepção de PCC sistematizadas nestes documentos, foram observados aspectos relacionados à articulação entre teoria e prática, à abordagem e à distribuição da carga horária de PCC no contexto das disciplinas do currículo. Uma ressalva a ser destacada diz respeito aos documentos analisados tendo em vista que durante a realização da pesquisa, em maio de 2017, foi aprovado o novo PPC do curso de Licenciatura em Geografia da UFG. Considerando a importância deste documento no que se refere à correção dos equívocos do projeto anterior, este foi inserido às análises da pesquisa, uma vez que aponta um novo cenário de compreensão da PCC no âmbito deste curso.

A articulação entre teoria e prática, para a UEG, baseando-se nas proposições legais vigentes, a exemplo do Art. 3o da Resolução CNE/ CP 02/2015 (já mencionada anteriormente), deve ser

Para0nde!?, Porto Alegre, v.10, n.2, p.28-35, 2018. Edição Especial com artigos publicados originalmente na XII ENANPEGE http://seer.ufrgs.br/paraonde 
fundamentada na indissociabilidade entre as atividades de ensino, pesquisa e extensão. Por outro lado, nas poucas linhas destinadas a abordar essa relação, em ambos os PPCs do curso da UFG, são destacadas proposições que valorizam a experiência discente ao longo do curso de formação e a prática é reconhecida como aquela que "atualiza e interroga a teoria" (GOIÁS, 2011, p. 07), implicando uma compreensão de que é a prática quem valida à teoria. Em suma, as discussões apresentadas sobre a articulação entre teoria e prática nestes documentos, em ambas as instituições, são sucintas e carecem de maior problematização.

Buscando adequar-se às legislações pertinentes, sobretudo às exigências das DCNs (BRASIL, 2002a; 2015), ambos os PPCs analisados apresentam a PCC como componente do currículo do curso. Tomam como referenciada os textos das Resoluções do Conselho Nacional de Educação e, também normativas institucionais. No caso da UEG a Resolução do Conselho Acadêmico 03/2015 (Estabelece as Diretrizes para a Prática como componente curricular nos cursos de Licenciatura no âmbito da Universidade Estadual de Goiás) e, no caso do PPC do curso na UFG (2011), a Resolução do Conselho de Ensino, Pesquisa, Extensão e Cultura 631/2003 (Define a política da UFG para a formação de professores da Educação Básica).

Tendo em vista que estas resoluções institucionais são tomadas como referências para a elaboração dos PPCs dos cursos, apresentamos apontamentos sobre elas: a primeira é uma normativa que trata especificamente da PCC no âmbito de todos os cursos da UEG, apresenta definições pautadas nas legislações vigentes e dispõe sobre doze diretrizes que devem nortear o desenvolvimento da PCC, relacionada à carga horária, ao tempo e espaço de desenvolvimento e articulação com as disciplinas do currículo, por exemplo.

A segunda é uma resolução que trata de toda a política de formação de professores na UFG, considerando o seu contexto de elaboração, visava orientar a reformulação curricular dos cursos de licenciatura para adequá-los às novas legislações (BRASIL, 2002a; 2002b) e assim apresenta um discurso de valorização da formação pedagógica, da pesquisa e da interdisciplinaridade. No entanto, não faz nenhuma menção à PCC. Destaca-se ainda que, nestes documentos, PPCs e resoluções institucionais, são incorporados os discursos presentes na legislação federal.

São enfatizadas, por exemplo, a prática articulada às demais disciplinas do currículo e não restrita aos Estágios Curriculares Supervisionados e a importância das atividades de observação, reflexão e resolução de situações problema. De modo geral, prevalece a incorporação dos discursos presentes na legislação, sobretudo, na compreensão do significado, dos objetivos e da organização destas no âmbito do currículo. A PCC, neste contexto, é compreendida como responsável por garantir a interdisciplinaridade nos cursos de formação de professores, sendo o elo de articulação entre as bases teóricas e metodológicas das disciplinas específicas e pedagógicas e o contexto da prática profissional, produz uma nova ordem de conhecimento.

No PPC do curso de Geografia da UFG de 2011, ainda que a expressão 'Prática como Componente Curricular' esteja explicitada e destacada no texto, a compreensão desta é equivocada no sentido de compreendê-la como carga horária para as disciplinas de formação pedagógica. No documento, afirma-se que "além das 400 (quatrocentas) horas previstas na Resolução CNE/CP 02, de 19/02/2002, a UFG permitiu a superposição, por meio da Resolução CEPEC n. 631/2003, de mais 160 (cento e sessenta) horas" (GOIÁS, 2011, p. 31). Amparados na normativa institucional de 2003, que é anterior aos esclarecimentos do Parecer CNE/ CP 15/2005, apontam para a compreensão de que às 400 (quatrocentas) horas de PCC integram as 576 (quinhentas e setenta e seis) horas em disciplinas de formação pedagógica do curso.

O PPC recentemente aprovado (GOIÁS, 2017) corrige os equívocos do anterior. Neste, a PCC é disposta como componente de todas as disciplinas do currículo e com sua carga horária específica, 400 (quatrocentas) horas, distribuídas nestas. Cabe-se destacar que, diferentemente dos demais PPCs analisados, neste a distribuição destas 400 (quatrocentas) horas ganha espaço na matriz curricular do curso, uma vez que, ao apresentar a carga horária de cada uma das disciplinas, também é apresentada a carga horária desta que é destinada ao desenvolvimento da PCC.

De modo geral, a PCC é compreendida, nos PPCs analisados, como uma prática formativa capaz de articular teoria e prática nas diferentes disciplinas de formação específica e pedagógica que integram os currículos, tal como é disposto nas legislações vigentes. Portanto, entendemos que esta deva

Para0nde!?, Porto Alegre, v.10, n.2, p.28-35, 2018. Edição Especial com artigos publicados originalmente na XII ENANPEGE http://seer.ufrgs.br/paraonde 
integrar as ementas das disciplinas, uma vez que é a partir delas que os professores formadores irão organizar os conteúdos curriculares e suas práticas pedagógicas. Passemos então a uma breve análise das ementas das disciplinas do curso.

No currículo do curso de Geografia da UEG, dentre suas 36 (trinta e seis) disciplinas, 18 (dezoito) dispõem, em suas ementas, sobre o desenvolvimento da PCC, sobretudo as disciplinas que tratam de conteúdos específicos da ciência geográfica (a exemplo de Climatologia, Geomorfologia, Geografia agrária, Geografia de Goiás e Cartografia). No caso do curso da UFG, este aspecto demarca a distinção entre os dois PPCs analisados: em 2011 a PCC não é referida nas ementas das disciplinas em momento algum enquanto no PPC de 2017 passa a contemplar todas as disciplinas do currículo, sem exceções.

Destaca-se que, no contexto desta análise, a composição das ementas destas disciplinas nos sugerem que a inserção da PCC foi uma imposição para adequar o PPC do curso à legislação. Essa percepção decorre de dois fatos: em primeiro lugar, pela redação textual da ementa que apresenta, sempre nas linhas finais, expressões como 'noções de [...] no ensino de Geografia' na educação básica', 'princípios de [...] no ensino de Geografia' na educação básica' e 'os conhecimentos de [...] no ensino de Geografia' (no caso do PPC da UEG) ou ainda a expressão "a disciplina no contexto profissional" como padrão em todas as ementas (no caso do PPC da UFG de 2017), o que sugere a proposição de uma aplicabilidade do conteúdo das disciplinas e, em segundo lugar, pelo fato de que nenhuma das disciplinas que propõe tal abordagem apresenta, dentre suas bibliografias, referências sobre o processo de ensino, especificamente, sobre o ensino de Geografia na Educação Básica.

Diante do exposto, podemos fazer três apontamentos: a) ambos os PPCs argumentam sobre a importância da PCC a partir da incorporação dos discursos presentes na legislação que, por sua vez, remetem às demandas disputadas pela comunidade epistêmica de formação de professores; b) apresentam discurso de valorização da prática que, embora distintos, adotam a investigação como princípio formativo; e c) dispõem sobre o desenvolvimento do componente prática de modo distinto: com sua carga horária distribuída dentre parte das disciplinas específicas e em atividades interdisciplinares (UEG) ou presente em todas as disciplinas que compõem o currículo do curso, com carga horária pré-estabelecida (UFG), deixando a critério do professor formador a definição do formato em que ela será desenvolvida no âmbito de sua disciplina.

\section{Considerações Finais}

É inegável que a reforma em questão representou significativas mudanças para os currículos dos cursos de licenciatura, sobretudo ao valorizar as especificidades da profissão e os conhecimentos didático-pedagógicos do professor. Todavia, a ênfase atribuída ao desenvolvimento de competências recai sobre a perspectiva de submeter o processo formativo dos professores à lógica da preparação para o mundo do trabalho, reforçando um viés pragmático e utilitarista para a formação. Ao destacar o caráter neotecnicista da reforma, buscou-se evidenciar que a vinculação desta proposta à política econômica neoliberal remete a um risco: a hipervalorização da prática pode recair em um esvaziamento teórico. Reside aqui a contradição que permeia a gênese da PCC: ao passo que se propõe a consolidação da identidade e da terminalidade dos cursos de licenciatura por meio da valorização das especificidades da profissão e de seus conhecimentos, se submete sua organização à lógica do saber-fazer docente em uma dimensão técnico-instrumental.

A leitura dos documentos curriculares alinhada às proposições do campo teórico leva à compreensão da PCC sob uma dupla determinação: do ponto de vista de seus fundamentos teóricometodológicos, está alicerçada na perspectiva de formar um professor dotado de competências investigativas e reflexivas para lidar com os dilemas advindos da prática profissional e, neste sentido, questões relacionadas ao fazer docente deveriam perpassar todo o percurso da formação inicial, dotando-o de uma preocupação permanente com as especificidades da profissão. Ressalta-se que a atenção dispensada às singularidades da prática pedagógica foi o maior avanço na proposta da PCC, entretanto, sua vinculação às dimensões técnico-profissionalizantes precisa ser tensionada.

Quando analisados os resultados contextuais da pesquisa, observaram-se diferentes 
configurações para a PCC, seja do ponto de vista de sua proposição nos documentos curriculares, seja do ponto de vista de seus encaminhamentos teórico-metodológicos. Embora cada instituição (UEG e UFG) e curso tenham interpretado e proposto o desenvolvimento da PCC de modo distinto, ressaltase que sua implementação foi permeada de incompreensões acerca de sua natureza e/ou do modo como deveria ser operacionalizada no currículo e nas práticas pedagógicas dos professores formadores. Tais incompreensões resultaram em diferentes interpretações que, no decurso das reestruturações curriculares pelas quais os cursos analisados passaram, dispuseram basicamente sobre questões relacionadas à distribuição da carga horária de PCC entre as disciplinas e, no caso da UEG, também sobre a atividade a ser desenvolvida para tal finalidade..

\section{Referências}

BERNSTEIN, Basil. A estruturação do discurso pedagógico: classe, códigos e controle. Vozes: Petrópolis, 1996.

BRASIL. Lei de Diretrizes e Bases da Educação Nacional. Lei número 9.394, 20 de dezembro de 1996.

BRASIL. Conselho Nacional de Educação/Ministério de Educação. Resolução 01/2002, de 18 de fevereiro de 2002. Institui as Diretrizes Curriculares Nacionais para a Formação de Professores da Educação Básica, em nível superior, curso de Licenciatura, de graduação plena. 2002a.

BRASIL. Conselho Nacional de Educação/Ministério de Educação. Resolução 02/2002, de 19 de fevereiro de 2002. Institui a duração e a carga horária dos cursos de Licenciatura, de graduação plena, de formação de professores da Educação Básica em nível superior. 2002b.

BRASIL. Conselho Nacional de Educação/Conselho de Ensino Superior. Parecer 15/2005. Esclarece as resoluções CNE/CP 01/2002 e CNE/CP 02/2002.

BRASIL. Conselho Nacional de Educação/Ministério de Educação. Resolução $n^{\circ}$ 02/2015, de $1^{\circ}$ de julho de 2015. Define as Diretrizes Curriculares Nacionais para a formação inicial em nível superior (cursos de licenciatura, cursos de formação pedagógica para graduados e cursos de segunda licenciatura) e para a formação continuada.

CAMPOS, Roselane Fátima. A reforma da formação inicial dos professores da Educação Básica nos anos de 1990: desvelando as tessituras da proposta governamental. Florianópolis, UFSC, Tese de doutorado, 2002, 242p.

CURADO SILVA, Kátia Augusta Pinheiro Cordeiro. Articulação teoria e prática na formação de professores: a concepção oficial. Revista Inter-Ação, Goiânia, v. 27, n. 02, p. 01-54, 2002.

DIAS, Rosanne Evangelista. Ciclos de políticas curriculares na formação de professores no Brasil (1996 - 2006). Rio de Janeiro, UERJ, Tese de doutorado, 2009, 248p.

DINIZ-PEREIRA, Júlio Emílio. A prática como componente curricular na formação de professores. Revista Educação, Santa Maria, v. 36, n. 2, p. 203-218, 2011.

GOIÁS. Universidade Federal de Goiás, Instituto de Estudos Socioambientais. Projeto Pedagógico do Curso de Licenciatura em Geografia, 2011.

GOIÁS. Universidade Estadual de Goiás. Campus de Ciências Sócio-Econômicas e Humanas. Projeto Pedagógico do Curso de Licenciatura em Geografia, 2015a. 
GOIÁS. Universidade Estadual de Goiás. Resolução Conselho Acadêmico 03/2015, de 12 de fevereiro de 2015. Estabelece as diretrizes para a prática como componente curricular nos cursos de Licenciatura no âmbito da Universidade Estadual de Goiás. Anápolis, 2015b.

GOIÁS. Universidade Federal de Goiás, Instituto de Estudos Socioambientais. Projeto Pedagógico do Curso de Licenciatura em Geografia, 2017.

PERRENOUD, Philippe. Dez novas competências para uma nova profissão. Pátio: Revista Pedagógica, Porto Alegre, v.5, n.17, p.8-12, 2001.

SCHÖN, Donald. Educando o profissional reflexivo: um novo design para o ensino e a aprendizagem. Porto Alegre: Artes Médicas, 2000.

SILVA, Luelí Nogueira Duarte. Formação de professores: dilemas e desafios da relação teoria e prática. Curitiba: Appris, 2013.

SOUZA-NETO, Samuel; SILVA, Vandei Pinto. Prática como componente curricular: questões e reflexões. Revista Diálogo Educacional, Curitiba, v. 14, n. 43, p. 889-909, 2014. 